\title{
Validity and reliability evidence of the questionnaire for illness representation, the impact of epilepsy, and stigma (QIRIS)
}

\author{
Evidências de validade e confiabilidade do questionário de representação da doença, \\ impacto da epilepsia e estigma (QIRIS) \\ Elisabete Abib Pedroso de Souza ${ }^{1}$, Karina Borges², Maria Cristina O. Santos Miyazaki², Karina da Silva \\ Oliveira ${ }^{3}$, Tatiana de Cássia Nakano
}

\begin{abstract}
The objective of this study was to obtain reliability and validity evidence for the questionnaire of illness representation, the impact of epilepsy, and stigma (QIRIS) for use with adolescents and adults in Brazil. QIRIS consists of 14 questions grouped in three domains (attribution of meaning, impact of disease, and stigma) and was applied to 57 adults with epilepsy. QIRIS internal consistency was satisfactory (Cronbach's $\alpha=0.866$ ). Significant and strong correlation was found between issues belonging to the same domain, as expected. Three domains have highly significant and positive correlations with the instrument's total score, indicating evidence of content validity. We conclude that QIRIS has psychometric properties and can facilitate a systematic evaluation of the patient's representation according to a biopsychosocial approach that may contribute to clinical practice based on scientific evidence.
\end{abstract}

Keywords: quality of life; stigma social; epilepsy; cognitive science; surveys and questionnaires.

\section{RESUMO}

Este estudo buscou evidências de confiabilidade e validade para o questionário de representação da doença, impacto da epilepsia e estigma (QIRIS), para uso em adolescentes e adultos no Brasil. O QIRIS consiste de 14 questões agrupadas em 3 domínios (atribuição de significados, impacto da doença e estigma) e foi aplicado em 57 adultos com epilepsia. A consistência interna do QIRIS foi satisfatória ( $\alpha$ de Cronbach $=0,866$ ). Foi encontrada forte e significante correlação entre as questões com o mesmo domínio.Os três domínios têm correlações altamente significativas e positivas com a pontuação total do instrumento, indicando evidências de validade de conteúdo. Concluímos que o QIRIS tem propriedades psicométricas que facilitam uma avaliação sistemática de representação do paciente de acordo com uma abordagem biopsicossocial, além de contribuir para uma prática clínica baseada em evidências científicas.

Palavras-chave: qualidade de vida; estigma social; epilepsia; ciência cognitiva; inquéritos e questionários.

There is growing literature indicating the importance of patient representation of illness in their behavioral responses to health threats ${ }^{1}$. Cognitive perception of the illness is studied on the basis of cognitive-behavioral approaches or other similar theories such as social cognition models or personal construct theory ${ }^{1}$. Cognitive activities that include thoughts, images and behaviors concerning an evaluation of the environment form a broad network of information that helps researchers understand how patients cope with the disease. Therefore, the environmental influences of a person's thoughts and feelings have an important contribution to behavioral health ${ }^{2,3}$.
Researchers in this field have made progress in the research of psychological health in epilepsy by examining the role of cognition and coping style ${ }^{4,5}$. This approach is increasing because patient perceptions explain greater differences in adaptation than biomedical variables ${ }^{4,6}$.

Epilepsy is a common neurological condition that affects the psychological adjustment and the quality, and it may therefore reveal a high incidence of fears, misunderstandings and stigma in these patients ${ }^{7.8}$. A chronic disease such as epilepsy can be an important stress factor, and the inability to deal with the condition can bring psychological difficulties

1 University of Campinas - UNICAMP, Faculdade de Medicina, Departamento de Neurologia, Campinas SP, Brasil;

²Faculdade de Medicina de São José Rio Preto, São José do Rio Preto SP, Brasil;

${ }^{3}$ Pontifícia Universidade Católica de Campinas, Centro de Ciências da Vida, Departamento de Psicologia, Campinas SP, Brasil.

Correspondence: Elisabete Abib Pedroso de Souza, Hospital Universitário death Campinas - UNICAMP; Caixa Postal - 6166; $13083-970$ Campinas, SP, Brasil; E-mail:souzaeap@yahoo.com.br

Conflict of interest: There is no conflict of interest to declare.

Received 16 November 2015; Received in final form 27 February 2016; Accepted 05 April 2016. 
and emotional distress ${ }^{9}$. Since one is diagnosed with epilepsy, having the disease activates a behavior modifying system of beliefs at the personal and social level. Furthermore, it involves expectations and perceptions that are individual intrapsychic categories related to each individual life story, which affects people in different manners?

An individual's beliefs about his/her symptoms, diagnosis, label, causality, perception of duration, consequences of the disease, and perception of control integrate his or her concept of "self" 10,11 with implications for feelings, behavior, and adjustment. Not only for the individual with epilepsy, but also for the entire family, especially because of the stigma related to this illness. The relationship between subjective variables, disease and socio-environmental demand is complex.

The illness representation theory supports the fact that all patients construct cognitive models of their illness, and also the fact that there is a dynamic relationship between its elements, where a patient's cognitive perception changes in line with illness experience and consequences ${ }^{1,7}$.

The first approaches related to illness beliefs were obtained from structured interviews with qualitative analysis without psychometric validation ${ }^{10}$ and other studies using a closed questionnaire with quantitative measures ${ }^{12,13}$. Kemp and Morley ${ }^{1}$ were the first to develop an interview that combines open questions and a structured questionnaire.

Based on Kemp's model, we developed a new psychological protocol in order to assess cognitive representations in adults and adolescents with epilepsy.

Therefore, this paper aimed to find reliability and validity evidence for the questionnaire of illness representation, the impact of epilepsy, and stigma (QIRIS) and its use in Brazil.

\section{METHOD}

\section{Development of measure}

Initially, the literature about related meanings, quality of life and stigma was reviewed.Some general points have emerged from this literature, such as: 1- All patients form representations early in the course of illness, and this representation affects individual perception of their quality of life and, especially, individual perception of discrimination and rejection; 2- For an assessment of these beliefs, it is important to make use of the psychological interview, to enable a qualitative analysis of subjective variables. In this study, the approach was to combine open-ended questions with rating scales, administrated in an interview format.

Aiming to evaluate how the impact of epilepsy is perceived in our environment, an open exploratory 16-question questionnaire was developed. It sought to contemplate the main domains of epilepsy representation and our clinical experience in epilepsy. Questionnaire respondents included 20 patients and 20 lay people from the local community ${ }^{14}$.
Briefly, the overall result showed that there is poor knowledge of epilepsy among interviewees, although most of them have received information from their doctors. Concerning the social aspects, most of them referred to difficulties in work and school environments, also in establishing relationships. The main epilepsy related feelings reported by the subjects included sadness, dependence, inferiority, insecurity, fear and pity $^{14}$. The open questionnaire was important to raise initial reactions about the concepts of epilepsy as well as the emotional and social adjustment.

Based on the results of this first questionnaire, a panel of three independent specialists evaluated the questions; afterwards, the most appropriate items were chosen ${ }^{15}$. The questionnaire used for the community had 16 closed questions about the medical (4 questions), social (10 questions) and personal (2 questions) areas. The patients questionnaire had four additional questions in the social and three in the personal area to be answered in the form of multiple-choice.The instrument was answered by 12 patients and 32 relatives from the Epilepsy Outpatients Clinic at the University Hospital of Campinas. Considering that patient beliefs are frequently influenced and reinforced by family members ${ }^{3}$, family beliefs should be investigated in parallel to the patients ${ }^{16}$ in a broader process of data collection.

The results are grouped in three main domains: medical, social and personal. Medical: patients and relatives did not know exactly what epilepsy is or how it is caused; nonetheless, they know how to treat it. Social: the most important areas where people with epilepsy are discriminated are work and social relationships. Patients also complained about their lack of freedom and limits on recreation activities. Personal: subjects apparently have the same feelings and thoughts about epilepsy and seizures ${ }^{15}$.

Therefore, at the present stage, in order to validate the instrument to assess the perception of stigma in the community, we selected the most common answers (50\% cut off) in order to create the items for a version of stigma scale of epilepsy (SSE) containing five questions, with twenty-four items ${ }^{17}$. According to the results, the points focused on the five-question scale were sufficient to achieve this objective ${ }^{18}$.

Our intention now is different, as we seek to understand the psychological (cognitive and emotional) aspects related to the disease, as important contingencies in adaptive reactions, from the perspective of the individual who has epilepsy.

The new questionnaire included answers identified in the social context (patients, relatives and community members) related to disease perception and impact, and as a psychological interview was drawn from questionnaires aimed at assessing cognitive representations. In this sense, it is important to note that the work of Weinman et al. ${ }^{13}$ and the research model developed by Kemp and Morley ${ }^{1}$ served as the basis for the final model that was selected as the basis for the scale proposed. 
The illness perception questionnaire (IPQ) $)^{13}$ comprises 5 brief scales assessing the core components of an illness representation and appears to be psychometrically sound. The five scales assess identity: 1) the symptoms the patient associates with the illness, cause; 2) personal ideas about etiology, time-line; 3) the perceived duration of the illness, consequences; 4) expected effects, and outcome and cure control; 5) how one controls or recovers from the illness. Each scale presents items whose content must be accepted or not by the patient.

Kemp and Morley ${ }^{1}$ aimed to assess six representation components of illness (identity, beliefs about symptoms and cause, consequences, beliefs about temporal course, control beliefs, self-illness relationship). The importance of the last one is based on the fact that the authors ${ }^{1}$ introduce open questions and include the item" consequences", which investigates perceived stigma and enacted stigma ${ }^{1}$.

It is important to say that this new instrument that we are investigating maintains, in the same way proposed by other models ${ }^{1}$, open questions about stigma perception, but it also includes constructs linked to quality of life. The ease and speed of the application and correction process, which is indeed easier than others, are shown in a differential work in a hospital.

This version of the questionnaire (Appendix) for illness representation, the impact of epilepsy, and stigma (QIRIS) was composed of 14 questions grouped in three domainsattribution of meaning, impact of the disease, and stigmaand was tested with the aim of investigating its psychometric properties. The results of validity and reliability of the questionnaire for illness representation, the impact of epilepsy, and stigma (QIRIS) will be presented.

\section{Subjects}

57 patients were involved in this study (71.93\% female and $28.07 \%$ male) who were assisted at the epilepsy clinic located in a University Hospital. Participant ages ranged between 21 and 62 years (21\% below 30 years, $26.32 \%$ aged $30-39$ years; $35.1 \%$ 40-49 years, and $17.54 \%$, above 50 years), $31.43 \%$ were single, separated or divorced, $61.86 \%$ were married; $7.7 \%$ were widowed; $56.14 \%$ were unemployed and $43.86 \%$ had a job; $68.42 \%$ have $\leq 8$ years of education; and $31.57 \%$ have $\geq 9$ years of education.

The clinical data indicated that $31.55 \%$ had focal seizures,54.39\% showed focal plus generalized seizures, and $14 \%$ had generalized seizures. Other data collected refer to the age at onset of seizures $(M=19.33, S D=12.3)$, disease $d u-$ ration $(\mathrm{M}=17.22, \mathrm{SD}=12.1)$, and medication (monotherapy: $85.7 \%$, polytherapy: $14.3 \%$ )

For this study, the inclusion criteria were: age between 18 and 65, ability to answer the questions, and presence of active epilepsy within the past 2 years. Patients were excluded if they had brain surgery, used concomitant medication with central nervous system effects, or had another progressive neurological or psychiatric illness.

UNICAMP's Committee of Ethics in Medicine approved this study. Written informed consent was obtained from the patients.

\section{Instruments}

1) Clinical and demographic identification questionnaire containing information on age, education, marital status, occupation, age of onset and duration of illness, seizure frequency, type of seizure and medication used.

2) The questionnaire for illness representation, the impact of epilepsy, and stigma (QIRIS) is composed of 3 parts: I) Attribution of meaning [three open questions: a) Q1 - Label; b) Q2 - Causal Attributions; and c) Q5 - Projecting Consequences; and four Likert questions: a) Q3 - Perceptions of Feelings; b) Q4 - Perception of Controllability; c) Q6 - Coping; and d) Q7 - Perception of Social Consequences]; II) Impact of Disease [a single open question: Q8 - Experience of difficulties; and two Likert questions: a) Q9 - Perceptions of difficulties; b) Q10 - Quality of Life], and III) Stigma [one open question: Q11 - Experience of Stigma; and three Likert questions: a) Q12 - Perceived Discrimination; b) Q13 - Stigma; and c) Q14 - Perceived Stigma].

In the Likert questions, subjects can choose 1 of 4 alternatives, indicating how much they agree with the content. Some items are inverted in the correction process (Q4, Q6.1, Q6.2, Q7.2, Q7.3, Q7.4, and Q10). The sum of the total in each area is achieved by adding the scores of all items. The total scale is calculated by adding the scores of the three areas. The higher the total score, the more negative beliefs and the greater the impact on patient health.

\section{Procedures}

Instruments were applied in the Applied Psychology Clinic of the Neurology University Hospital, UNICAMP, Campinas/SP, Brazil. Patients completed the identification protocol and the questionnaire under the same conditions. The instruments were administered as an interview in adults with epilepsy.

\section{RESULTS}

Statistical analyses were performed using version 16.0 of the Statistical Package for Social Sciences (SPSS) for Windows.Reliability was assessed by tests of internal consistency for each domain using Cronbach's alpha coefficient. The results are presented in Table 1. In the second analysis, the Spearman correlation was calculated between items (inter-score correlation) (Table 2). At the end, the correlation between domains assessed by the Questionnaire was calculated (Table 3 ). 
To carry out the statistical analysis, some QIRIS scores have to be reversed. These items are: Q4, Q6.1, Q6.2, Q7.2, Q7.3, Q7.4, Q10. It is also important to note that Q4 (Perception of Controllability), Q10 (Quality of Life), and Q13 (Stigma) domains comprise only one item each, so Cronbach's coefficient is not calculated for these cases.

The analysis of internal consistency generally showed that all items presented high values. Similarly, the total score also showed an adequate value (0.866). Considering each domain separately, we can see that Domain 1 - Attribution of meaning presented a .763 internal consistency. The results of the items that composed this domain showed good values for Q3 (.771), moderate value for Q7 (.559) and lower consistency for Q6 (.215). In Domain 2 - Disease impact, consistency was .794 (Q9 presented a .775 value). Domain 3 - Stigma had .842 internal consistency and its Q9 and Q14 areas had .773 and .733 , respectively.

We can thus verify that the questionnaire had good internal consistency. The exception occurs in the Q7 - Social Consequences domain, which is lower than other domains, and in the Q6 - Coping domain, which presented an inadequate value. This is why future studies should consider removing Q6.4 (item with the least consistency). For the time

Table 1. Internal consistency of QIRIS questionnaire.

\begin{tabular}{|cc|}
\hline Part / Domains & $\begin{array}{c}\text { Cronbach's alpha } \\
\text { coefficient }\end{array}$ \\
\hline Part 1 - Attribution of Meaning & .763 \\
\hline Q3 - Perception of Feelings & .771 \\
\hline Q6 - Coping & .215 \\
\hline Q7 - Social Consequences & .559 \\
\hline Part 2 - Disease Impact & .794 \\
\hline Q9 - Perception of Difficulties & .755 \\
Part 3 - Stigma & .842 \\
\hline Q12 - Perceived Discrimination & .773 \\
Q14 - Perceived Stigma & .733 \\
\hline Total & .866 \\
\hline
\end{tabular}

being, in face of the small sample size, we can consider that the questionnaire presented good psychometric standards related to reliability.

In order to understand the internal stability of the instrument, we investigated the correlations between the scores of items of the questionnaire ${ }^{19}$. This analysis was based on Spearman's correlation coefficient and is shown in Table 2.

According to the data, positive and significant correlations were found between Q6 and Q7 ( $\mathrm{r}=0.53, \mathrm{p} \leq 0.001)$, Q9 and Q10 ( $\mathrm{r}=0.57, \mathrm{p} \leq 0.001), \mathrm{Q} 12$ and Q13 ( $\mathrm{r}=0.43, \mathrm{p} \leq$ $0.01)$, and $\mathrm{Q} 12$ and $\mathrm{Q} 14(\mathrm{r}=0.72, \mathrm{p} \leq 0.0001)$. The correlations between Q3 and Q4 was negative (-0.78, $\mathrm{p} \leq 0.0001)$.

Remarkably, in Domain 1 - Attribution of meaning, the correlation between Perception of Feelings (Q3) and Perception of Controllability (Q4) was significant, but negative. Positive and significant correlations between the questions that evaluate Coping (Q6) and Perception of social consequences (Q7) were also observed. In Domain 2 - Impact of Disease, the correlation between Perception of difficulties (Q9) and Quality of Life (Q10) was significant and positive; in Domain 3 - Stigma, the correlation between Perceived Discrimination (Q12) and Stigma (Q13) as well as the correlation between Perceived Discrimination (Q12) and Perceived Stigma (Q14) were positive and significant. The only relationship that was not significant occurred between Q13 (Stigma) and Q14 (Perceived Stigma), belonging to the Stigma Domain.

Considering that we hypothesized significant and strong correlations between issues belonging to the same domain, it was possible to note that most results met the expectations.

Table 3 shows an analysis of correlations between the domains of the instrument. Therefore, it is possible to observe that the three domains have highly significant positive correlations with the total score of the instrument, Part $1(\mathrm{r}=0.52 ; \mathrm{p} \leq 0.001)$, Part $2(\mathrm{r}=0.75 ; \mathrm{p} \leq 0.0001)$, and Part $3(r=0.66 ; p \leq 0.0001)$. It is also worth pointing out that Part 1 and Part 3 had a positive and significant correlation with each other $(r=0: 35 ; p \leq 0.01)$.

Table 2. Spearman correlations between items of QIRIS questionnaire.

\begin{tabular}{lcccccccc}
\hline Item & Q3 & Q4 & Q6 & Q7 & Q9 & Q10 & Q12 & Q13 \\
\hline Q4 & $-0.78^{\star \star \star}$ & - & - & - & - & - & - \\
Q6 & 0.12 & -0.18 & - & - & - & - & - \\
Q7 & 0.35 & -0.32 & $0.53^{\star \star}$ & - & - & - & - & - \\
Q9 & 0.06 & 0.18 & 0.24 & 0.21 & - & - & - & - \\
Q10 & -0.03 & 0.13 & -0.04 & 0.04 & $0.57 * \star$ & - & - & - \\
Q12 & 0.09 & 0.05 & 0.05 & 0.22 & 0.26 & 0.03 & - & - \\
Q13 & 0.15 & 0.01 & -0.09 & -0.10 & 0.01 & -0.02 & $0.43^{\star}$ & - \\
Q14 & 0.05 & 0.02 & 0.21 & 0.30 & 0.29 & 0.06 & $0.72^{\star \star *}$ & -0.14 \\
\hline
\end{tabular}

${ }^{*} p \leq 0.01 ;{ }^{* *} p \leq 0.001 ;{ }^{* *} p \leq 0.0001$ 
Table 3. Spearman correlations between QIRIS domains.

\begin{tabular}{lccc}
\hline Variable & Part1 & Part2 & Part3 \\
\hline Part2 & .16 & - & - \\
Part3 & $.35^{\star}$ & .14 & - \\
Total & $.52^{\star \star}$ & $0.75 * \star \star$ & $0.66^{\star \star \star}$ \\
\hline
\end{tabular}

$* p \leq 0.01 ; * * p \leq 0.001 ; * * * p \leq 0.0001$

The purpose of the open questions in this questionnaire is to provide a qualitative analysis, though this type of analysis was not the subject of this paper. However, we found it interesting to show that the open questions are related to one another, and thus established the criteria considering the question that starts each domain. These questions were categorized and the analysis involved the Mann-Whitney test and showed interesting and expected results.

The results showed that the Q1-Label related with Diagnosis (Yes / No) was significant with Q9 -Perceptions of Difficulties ( $p=0.004)$. Furthermore, Q1 - Meaning of epilepsy (Negative / Positive) showed significant differences for Coping - Q6 ( $p=0.043)$, Perceptions of Difficulties - Q9 $(p=0.039)$, and had significant correlation with the total score of Part 2 - Quality of life $(\mathrm{p}=0.039)$ and Total score of QIRIS ( $\mathrm{p}=0.045)$. Open question Q8 - Experience of Difficulties was significant with Q9 - Perceptions of Difficulties $(p=0.004)$ and total score of Part 2 - Quality of life ( $p=0.005) . Q 11$ - Stigma experience (Negative / Positive) was not associated with any question of the QIRIS.

The validity based on Mann-Whitney test was performed to examine the relationship between the scores of the QIRIS and socio-demographic variables.No Employed was significant with Part1 and Part3 ( $\mathrm{p}=0.028$ and $\mathrm{p}=0.035$, respectively) and also with questions Q3 $(p=0.023)$, $Q 4(p=0.0054)$, and Q13 $(p=0.021)$. The relationship between Marital status and Perceived stigma (Q14) was significant $(p=0.048)$. Education was positively related with Part1 $(\mathrm{p}=0.049)$. Based on Kruskall-Wallis test, we compared the clinical variables that showed differences between focal plus generalized seizures and generalized seizures $(p=0.047)$.

\section{DISCUSSION}

This study aimed to describe a new questionnaire to assess epilepsy representations, impact of disease and stigma. The purpose comprised the psychological (cognitive and emotional) aspects related to the disease as important contingencies in adaptive reactions.

During the development of the questionnaire process and the search for validation evidence, an important step to mention is the need for methodological accuracy in relation to the theoretical background, objectives, and conditions that will emerge and the level of analysis (use in clinical practice or research). Based on that, all phases of the study related in this paper were important.

The new questionnaire, as a psychological interview, was drawn from questionnaires aimed to assess cognitive representations, including the answers identified in the social context (patients, relatives, and community people). This is a major contribution and an advantage.

In this sense, the questionnaire showed good psychometric standards. The QIRIS items proved to be interdependent and homogeneous in terms of the concepts they measure, as indicated by the Cronbach coefficients and scale inter-correlation. Reliability and accuracy were satisfactory.

Although questions Q6 and Q7 were slightly below 0.70 in the Cronbach analysis, these items appear closely related in scale inter-correlation.

We hypothesized strong correlations among questions with the same content and that has been showed in several studies, ${ }^{9,2021}$. People who perceive poor control of the disease $(\mathrm{Q} 4)$ are found to usually experience more negative feelings (Q3), and this was a highly significant correlation. An important psychological aspect to be highlighted is the belief that they have little personal control, and such a general outlook is associated with a more passive stance and depressive thinking ${ }^{22}$.

Thus, positive correlations were also expected between questions Q6 and Q7, which assess coping and social consequences, and this result was confirmed. Inappropriate strategies are known to contribute to distortions in social perception and to negative assessment of the social consequences ${ }^{7,9}$.

Similarly, questions Q9 and Q10 showed a high correlation, reinforcing the concept that the perception of difficulties in everyday life is associated with a worse assessment of patient well-being/quality of life ${ }^{7,9}$. Question Q12 sought to assess perception of discrimination and showed highly significant correlation with questions assessing perceived stigma (Q13) and internalized discrimination (Q14). Several studies ${ }^{20,21}$ call attention to the fact that, after a situation is evaluated stressful, the patient usually experiences negative feelings and dysfunctional behaviors. Souza and Salgado ${ }^{9}$ also discuss the psychological process involved.

The three areas also showed highly significant correlations with the total QIRIS score. These results can reinforce the evidence of construct validity (when the empirical data confirm the theory) and content validity ( fulfilling important aspects of the investigated construct $)^{19}$. The investigation of other types of validity evidence, for example, criteria validity and factor analysis could help researchers to verify the instrument dimensionality and add important results to the process of instrument construction.

We can see that the instrument enables an interconnection of the different aspects involved in evaluating the disease, supporting the concept that cognitive representations 
are individual, and controlling the way patients deal with the disease also affects adjustment, well-being and the perception of stigma ${ }^{9,10,11}$.

Another aspect in this study was to combine open-ended questions with rating scales, administrated in interview format. In our study, open questions were important to activate relevant ideas and emotions related to epilepsy, according to Antonak and Rankin ${ }^{23}$. Following the model developed by Kemp and Morley ${ }^{1}$, we were the first to develop an interview combining open questions and a structured questionnaire to assess six representation components of illness.

In our attempt to test if open questions related with other QIRIS questions, the results were satisfactory, explaining more variables and their contents.

Remarkably as well, when we take into account Brazil's socioeconomic reality, the use of perception inventories through interviews assists people with low education. For that population, it is better to avoid the use of abstract terminology, extensive instructions, and wide ranging contents $^{24}$. Accordingly, the use of both open questions and the Likert type of questions enabled the authors to collect more reliable data. This is one of the contributions that the instrument aims to bring to the area, as it offers broader and more adequate possibilities to evaluate the different population strata in terms of educational and social level.

In recent decades, there has been greater interest in the study of variables that control the impact of epilepsy, variables that go beyond the seizures, remarkably the importance of psychosocial conditions and their influence in determining the well-being of individuals in chronic medical conditions. In contrast to the medical model, the socio-psychological model assumes that other personal characteristics affect the degree to which patients feel affected in their well-being and stigmatized by their condition ${ }^{2,22}$.

Alongside the development of measures is a need to increase our knowledge of the functional dimensions associated with neurological disorders.

The result of the assessment depends on information brought by the individual patient and his/her symptoms, behavioral patterns, perceptions of the disease, and aspects of his/her life. This approach encourages clinicians to see patients as active processors and theorists of their condition, and to examine the condition from a patient's perspective.

This is inherently a psychological approach that has the potential to provide greater understanding of what guides patients' behavior ${ }^{3,25}$. Chronic diseases involve a large number of behavioral variables, and the scientific question that emerges is: how to explain the relationship between behavior and health and behavior and disease, and how to demonstrate control of this relationship?

We believe that this instrument is a promising tool in clinical evaluation and research on adults with epilepsy. The results presented in this paper showed that the QIRIS presents psychometric properties and it is a valid and reliable instrument to assess the psychological aspects related with the meaning of the disease and the interrelation between quality of life and stigma.

Considering that the research reported here consists of the first studies with the instrument, and before the positive findings, future studies will have to be conducted in order to investigate other aspects not covered here. Such analysis will allow new evidence of the quality of the proposed instruments, as well as their suitability for its purpose and target population.

\section{References}

1. Kemp S, Morley S. The development of a method to assess patients' cognitive representations of epilepsy. Epilepsy Behav. 2001;2(3):247-71. doi:10.1006/ebeh.2001.0179

2. Kendall PC. Guiding theory for therapy with children and adolescents. In: Kendall PC, editor. Child and adolescent therapy: cognitive-behavioral procedures. 3rd ed. New York: Guilford; 2006. p. 3-32.

3. Hirani SH, Newman SP. Patients' beliefs about their cardiovascular disease. Heart. 2005;91(9):1235-39. doi:10.1136/hrt.2003.025262

4. Kemp S, Morley S, Anderson E. Coping with epilepsy: do illness representations play a role? Br J Clin Psychol. 1999;38(1):43-58. doi:10.1348/014466599162656

5. Upton D, Thompson PJ. Effectiveness of coping strategies employed by people with chronic epilepsy. J Epilepsy. 1992;5:119-27. doi:10.1016/S0896-6974(05)80059-3

6. Meador KJ. Research use of the news quality of life of epilepsy inventory. Epilepsia. 1993;34(suppl 4):34-8. doi:10.1111/j.1528-1157.1993.tb05914.x

7. Souza, E.A.P. [Protocol of quality of life in epilepsy: preliminary results]. Arq Neuropsiquiatr. 2001;59(3A):541-4. Portuguese. doi:10.1590/S0004-282X2001000400011
8. Li LM, Sander JW. [National demonstration project on epilepsy in Brazil]. Arq Neuropsiquiatr. 2003;61(1):153-6. Portuguese. doi:10.1590/S0004-282X2003000100033

9. Souza EAP, Salgado PCB. A psychosocial view of anxiety and depression in epilepsy. Epilepsy Behav. 2006;8(1):232-8. doi:10.1016/j.yebeh.2005.10.011

10. Leventhal, H.;Nerenz, D.R. The assessment of illness cognition. In: Karole P, editor. Measurement strategies in health psychology. New York: Wiley; 1986. p. 517-54

11. Leventhal $H$, Diefenbach M. The active side of illness cognition. In: Skelton JA, Croyle RT, editors. Mental representations in health and illness. New York: Springer, 1991.

12. Turk DC, Rudy TE, Salovey P. Implicit models of illness.J Behav Med. 1986;9(5):517-54. doi:10.1007/BF00845133

13. Weinman J, Petrie KJ, Moss-Morris R, Horne R. The illness perception questionnaire: a new method for assessing the cognitive representations of illness. Psychol Health. 1996;11(3):431-45. doi:10.1080/08870449608400270

14. Fernandes PT, Salgado PC, Noronha ALA, Barbosa FD, Souza EA, Li LM. Stigma Scale of Epilepsy: conceptual issues. J Epilepsy Clin Neuropshysiol. 2004;10:213-8. 
15. Salgado PC, Fernandes PT, Noronha AL, Barbosa FD, Souza EA, Li LM. The second step in the construction of a stigma scale of epilepsy. Arq Neuropsiquiatr. 2005;63(2B):395-8. doi:10.1590/S0004-282X2005000300005

16. Freitas-Lima P, Monteiro EA, Macedo LR, Funayama SS, Ferreira Fl, Matias Júnior I et al .The social context and the need of information from patients with epilepsy: evaluating a tertiary referral service. Arq Neuropsiquiatr. 2015;73(4):298-303. doi:10.1590/0004-282X20150007

17. Fernandes PT, Salgado PC, Noronha AL, Sander JW, Li LM. Stigma scale of epilepsy: validation process. Arq Neuropsiquiatr. 2007;65(suppl 1):35-42. doi:10.1590/S0004-282X2007001000006

18. Fernandes PT, Noronha AL, Sander JW, Li LM. Stigma scale of epilepsy: the perception of stigma in different cities in Brazil. Arq Neuropsiquiatr. 2008;66(3A):471-6. doi:10.1590/S0004-282X2008000400006

19. Bowling A. Measuring health: a review of quality of life measurements scales. Buckingham: Open University Press; 1997.
20. Kanner AM. Depression in epilepsy is much more reative process. Epilepsy Currents. 2003;3(6):202-3. doi:10.1046/j.1535-7597.2003.03609.x

21. Suurmeijer TP, Reuvekamp MF, Aldenkamp BP. Social functioning, psychological functioning, and quality of life in epilepsy. Epilepsia. 2001;42(9):1160-8. doi:10.1046/j.1528-1157.2001.37000.x

22. Herman B, Jacoby, A. The psychosocial impact of epilepsy in adults. Epilepsy Behav. 2009;(15):S11-6. doi:10.1016/j.yebeh.2009.03.029

23. Antonak F, Rankin PR. Measurement and analysis of knowledge and attitudes toward epilepsy and persons with epilepsy. Soc Sci Med. 1982;16(30):1591-3. doi:10.1016/0277-9536(82)90170-8

24. Rosal MC, Carbone ET, Goins KV. Use of cognitive interviewing to adapt measurements for low-literate Hispanics. Diabetes Educ. 2003;29(6):1006-17. doi:10.1177/014572170302900611

25. Sawant N, Kinra V. An Indian study on perceptions of patients of epilepsy and their family to stigma and its impact on quality of life. Am J Clin Neurol Neurosurgery. 2015;1(1):1-9. 
APPENDIX: QUESTIONNAIRE OF ILLNESS

REPRESENTATION, EPILEPSY'S IMPACT AND

STIGMA (QIRIS)

This interview is important to know what you think and feel about what you have and we can serve you better.

You will answer some questions that are open and in others you must choose one of the scale: 1-Never, 2- Rarely, 3-Often, 4-Always.

\section{PART 1 - ATTRIBUTION OF MEANING}

1. Label.

1.1 What the name or diagnosis about the symptoms that you have?

\subsection{What meaning have seizure /epilepsy that you} experienced?

\section{Causal attributions}

What do you think caused epilepsy in your case?

\section{Perception of Feelings}

What do you feel when you are in seizures?

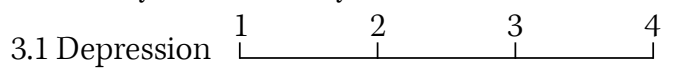

3.2 Shock $\begin{array}{llll}1 & 2 & 3 & 4 \\ & \perp & 1\end{array}$

3.3 Fear $\begin{array}{llll}1 & 2 & 3 & 4 \\ \end{array}$

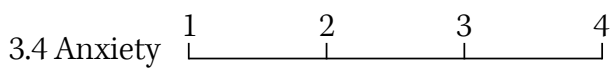

3.5 Sorry for yourself \begin{tabular}{llll}
1 & 2 & 3 & 4 \\
\cline { 2 - 2 }
\end{tabular}

3.6 Others

\section{Perception of Controllability}

Do you think that you have control over your seizure?

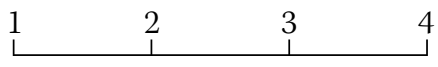

\section{Projecting consequences}

How you imagine your future having seizures?

\section{Coping}

How the people with epilepsy often act?
6.1 Talking to persons about disease.

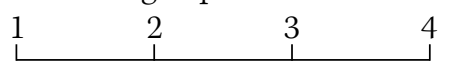

6.2 Looking for medical treatment.

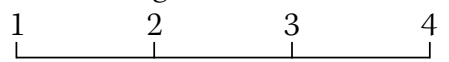

6.3 Withdrawal \begin{tabular}{rrrr}
1 & 2 & 3 & 4 \\
\hline
\end{tabular}

6.4 Act as if they had not epilepsy

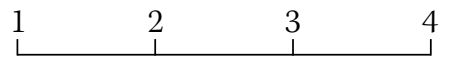

6.5 Others

\section{Perception of Social Consequences}

What do you guess people think to see someone having seizure?

\begin{tabular}{lllll} 
7.1 Fear & 1 & 2 & 3 & 4 \\
\cline { 2 - 4 } 7.2 Pity & 1 & 2 & 3 & 4 \\
\cline { 3 - 5 } & 1 & 1
\end{tabular}

7.3 Theyknowit's aseizure $\begin{array}{llll}1 & 2 & 3\end{array}$

7.4 Help $\begin{array}{rrrr}1 & 2 & 3 & 4\end{array}$

7.5 They think that it is a contagious disease

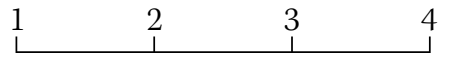

7.6 Others

\section{PART 2- IMPACT OF DISEASE ( QUALITY OF LIFE)}

\section{Experience of difficulties}

Can you talk about some difficulties which you have because of your seizures?

\section{Perceptions of difficulties}

Which difficulties do you think that people with epilepsy have in their daily life?

9.1 Family relationships 1

9.2 Employment $\begin{array}{llll}1 & 2 & 3 & 4 \\ & & & \end{array}$

9.3 School $\begin{array}{llll}1 & 2 & 3 & 4 \\ & 1 & 1 & \end{array}$

9.4 Friendship / Dating \begin{tabular}{rrrr}
1 & 2 & 3 & 4 \\
\hline
\end{tabular}

9.5 Sexuality \begin{tabular}{llll}
1 & 2 & 3 & 4 \\
\cline { 3 - 4 } & & 1 & 1
\end{tabular}

9.6 Emotional $\begin{array}{llll}1 & 2 & 3 & 1\end{array}$

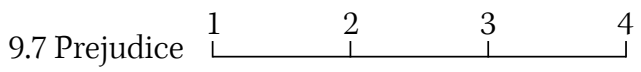


9.8 Health

1

(1)

\section{Quality of life}

What score would you rate your quality of life (satisfaction in the aspects mentioned above, as follows: 1 = poor, 10 = great) ?

\begin{tabular}{rrrrrrrrrr}
1 & 2 & 3 & 4 & 5 & 6 & 7 & 8 & 9 & 10 \\
\hline & 1 & 1 & 1 & 1 & 1 & 1 & 1 & 1 & 1 \\
\hline
\end{tabular}

\section{PART 3 - EXPERIENCE OF STIGMA}

11. Can you tell of any situation where people have actually treaded you unfairly because you having seizure.

\section{Perceived discrimination}

In what situation do you think a person with epilepsy is discriminated?

12.1 Family relationships $\begin{array}{llll}1 & 2 & 3 & 4 \\ \end{array}$

12.2. Friendship \begin{tabular}{llll}
1 & 2 & 3 & 4 \\
\hline
\end{tabular}

12.3. Employment \begin{tabular}{llll}
1 & 2 & 3 & 4 \\
\cline { 2 - 3 }
\end{tabular}

12.4. School $\begin{array}{llll}1 & 2 & 3 & 4 \\ \end{array}$

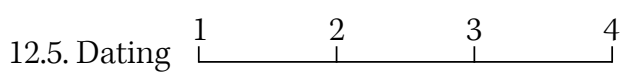

\section{Stigma}

What score would you rate for the prejudice that the general population has towards epilepsy ( $1=$ no prejudice, 10 = maximum prejudice)?

\begin{tabular}{rrrrrrrrrr}
1 & 2 & 3 & 4 & 5 & 6 & 7 & 8 & 9 & 10 \\
& 1 & 1 & 1 & 1 & 1 & $\perp$ & $\perp$ & 10 & 10 \\
\hline
\end{tabular}

\section{Perceived Stigma}

Do you agree?

14.1 I care when people are afraid of me because of epilepsy

\begin{tabular}{rrrr}
1 & 2 & 3 & 4 \\
& 1 & 1 & । \\
\hline
\end{tabular}

14.2 I care when people do not take my opinions as seriously as would take if I had not epilepsy.

$\begin{array}{rrrr}1 & 2 & 3 & 4 \\ \llcorner & 1 & 1 & 4\end{array}$

14.3 I consider myself imperfect because of epilepsy.

$\begin{array}{rrrr}1 & 2 & 3 & 4 \\ & 1 & 1 & \text { I }\end{array}$

14.4 People who know I have seizures treat me differently \begin{tabular}{llll}
1 & 2 & 3 & 4 \\
\hline
\end{tabular}

14.5 I have few friends because I have epilepsy

$\begin{array}{rrrr}1 & 2 & 3 & 4 \\ & 1 & 1 & 4\end{array}$

14.6 I care what people think of me when they saw me having a seizure.

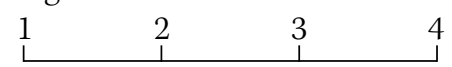

